\title{
Water Hyacinth Report
}

\author{
Mike Griffel
}

December 2018

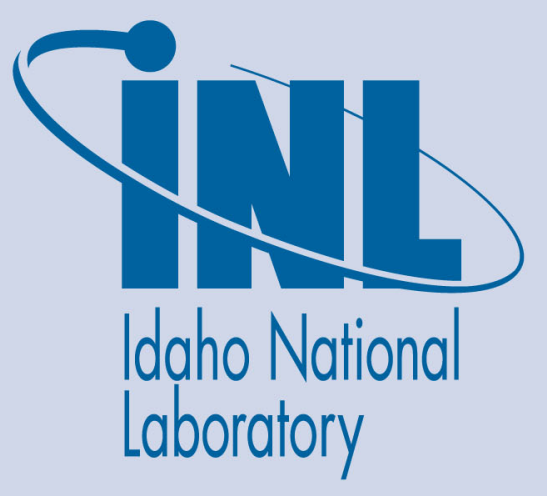

The INL is a U.S. Department of Energy National Laboratory operated by Battelle Energy Alliance 
INL/EXT-18-51742-Revision-0

\title{
Water Hyacinth Report
}

\author{
Mike Griffel
}

December 2018

\section{Idaho National Laboratory} Idaho Falls, Idaho 83415

http://www.inl.gov

Prepared for the U.S. Department of Energy Office of Nuclear Energy Under DOE Idaho Operations Office Contract DE-AC07-05ID14517 


\title{
Spatial Analysis Resources for Locating and Planning Centralized Water Hyacinth Biomass Operations in Togo and the Lake Victoria Region in Kenya
}

\author{
L. Michael Griffel, Tessica A. Gardner, \& Veronika Vazhnik
}

\section{Executive Summary}

Water hyacinth (Eichhornia crassipes) is a fast-growing, invasive aquatic species and represents a potential biomass resource for bioenergy production in the Togo and Kenya regions on the African continent. Literature shows multiple conversion pathways exist to produce energy from water hyacinth while supporting economic growth, job creation, and environmental sustainability. $\mathrm{ECO}_{2}$ LIBRIUM $\left(\mathrm{ECO}_{2}\right)$ is investigating the feasibility of developing feedstock logistics modelling capabilities to facilitate water hyacinth based bioenergy production. Developing a water hyacinth feedstock pipeline capable of supplying biomass at consistent quantity and quality requires sophisticated feedstock logistics modelling to minimize costs while maximizing ecosystem services. However, developing this type of modelling capability requires specific spatial data and analysis resources. Idaho National Laboratory (INL) maintains research capabilities in the areas of bioenergy, feedstock logistics, spatial analysis, and remote sensing. INL researchers have compiled spatial data and analysis resources in this report to back development of a water hyacinth biomass feedstock logistics model.

\section{Introduction}

Access to affordable, reliable, secure, and renewable energy resources is a key component of thriving local, regional, and national economies. In the age of finite energy resources, renewable biomass resources can provide cost-effective substitutes for traditional fossil-fuels such as diesel, gasoline, and coal as well as curb deforestation rates. Unfortunately, many people in developing worlds don't have access to energy resources to fulfill basic energy needs and rely on unsustainable deforestation practices to supply current biomass resources. About 1.6 billion people globally, mostly in Sub-Saharan Africa, Asia, and Latin America lack access to electricity while 2.5 billion rely on traditional biomass such as wood for cooking and heating (Demirbas and Demirbas, 2007). Although Africa has extensive arable land, the continent suffers from food insecurity, poverty, and lack of developed energy resources. The development of bioenergy resources and regional bio-economies in Africa would provide several important benefits to offset these challenges including new employment opportunities, development of infrastructure, energy democratization, and potential restoration of degraded lands while disproportionately benefiting rural and impoverished areas (Lynd et al., 2015).

Water hyacinth is abundant and could potentially be used as a biomass feedstock for bioenergy production for many regions in Africa. As a fast-growing and invasive aquatic plant species, this non-native, free-floating plant negatively impacts irrigation, growth, and development of other aquatic species, and can physically obstruct entire waterways. Growth rates in favorable conditions have reached 17.5 metric tons per day (Kunatsa et al., 2013). Targeted harvesting of water hyacinth could reduce deforestation rates and also result in ecosystem services benefits by reducing water hyacinth population pressure and preserving or improving water quality.

Table 1 shows the chemical characteristics of water hyacinth. The use of water hyacinth as a bioenergy feedstock has been documented for several conversion pathways including cellulosic ethanol, biogas, and biomass densification (bio-briquetting) (Rezania et al., 2015). Water hyacinth consists of $30-55 \%$ (dry weight) of hemicellulose and has been used in 
bioconversion to ethanol by yeast fermentation (Nigam, 2002). Lu et al. showed combining pig manure and water hyacinth consistently produce higher levels of biogas than pig manure alone likely due to the improved carbon-to-nitrogen $(\mathrm{C} / \mathrm{N})$ ratio and lignin content in the mixed fermentation feedstock (Lu et al., 2010). Research has also shown combinations of water hyacinth and empty fruit bunch fibers compressed into bio-briquettes showed great potential as an alternative source to coal with reduced greenhouse gas emission rates (Rezania et al., 2016).

Table 1. Chemical composition of water hyacinth (Source Rezania et al., 2015).

\begin{tabular}{cccccc}
$\%$ Moisture & $\%$ Nitrogen & $\%$ Ash & $\% \mathbf{P}_{2} \mathbf{O}_{5}$ & $\% \mathbf{K}_{2} \mathbf{O}$ & $\%$ Organic Matter \\
\hline \hline 95.5 & 0.04 & 1.0 & 0.06 & 0.20 & 3.5 \\
\hline
\end{tabular}

Although extensive literature and research results show water hyacinth is abundant and significant ancillary benefits exist related to harvest and control of the species' population that could minimize biomass costs, development of modelling capabilities are needed to reduce feedstock logistics costs relative to water hyacinth harvest and collection, transportation, storage, and preprocessing steps. However, spatial data and analysis is needed to facilitate spatial and temporal resource assessments. For example, transportation networks and end-user locations are instrumental to modelling supply chain logistics costs and reliability. This has been shown in previous INL analysis supporting the development of pioneering cellulosic ethanol bioeconomies (Hess et al., 2007). Fortunately, extensive, publically-available spatial data exist in varying formats with this type of information. A large amount of peer-reviewed literature also exists demonstrating successful water hyacinth mapping techniques utilizing advanced remote sensing technologies. The following sections will outline useful datasets, literature, and other resources to support development of a water hyacinth supply chain model. The sections will include publically available spatial data denoting population centers, transportation features, water bodies, and remote sensing data. Analysis methodologies and Geographic Information Systems (GIS) software with suitable analysis capabilities will also be highlighted. It is not the authors' intention to detail every potential source but specific and relevant sources of data which could be incorporated into analysis and model development.

\section{Spatial Vector Data}

The OpenStreetMap (OSM) project has compiled an extensive amount of free spatial data in points, lines, and polygons on a global scale and is freely available under an open source license (Contributors, 2012). A community of users and contributors continually update datasets delineating human population center (i.e. cities, towns, etc.), transportation networks (rail, automobile, bicycle, etc.), points of interest, water bodies, and various land use features. OSM data is available either as streaming services utilized in GIS software or can be downloaded in common spatial data file formats such as shapefiles for specific regions.

Figure 1 shows OSM point features data for "places" in Togo. These point features include categorical descriptions for population centers including "hamlet", "village", "town", "suburb", and additional categories. This type of data is very useful to identify clusters of human population nodes and model logistics and transportation costs from biomass feedstock source points to potential end users. 


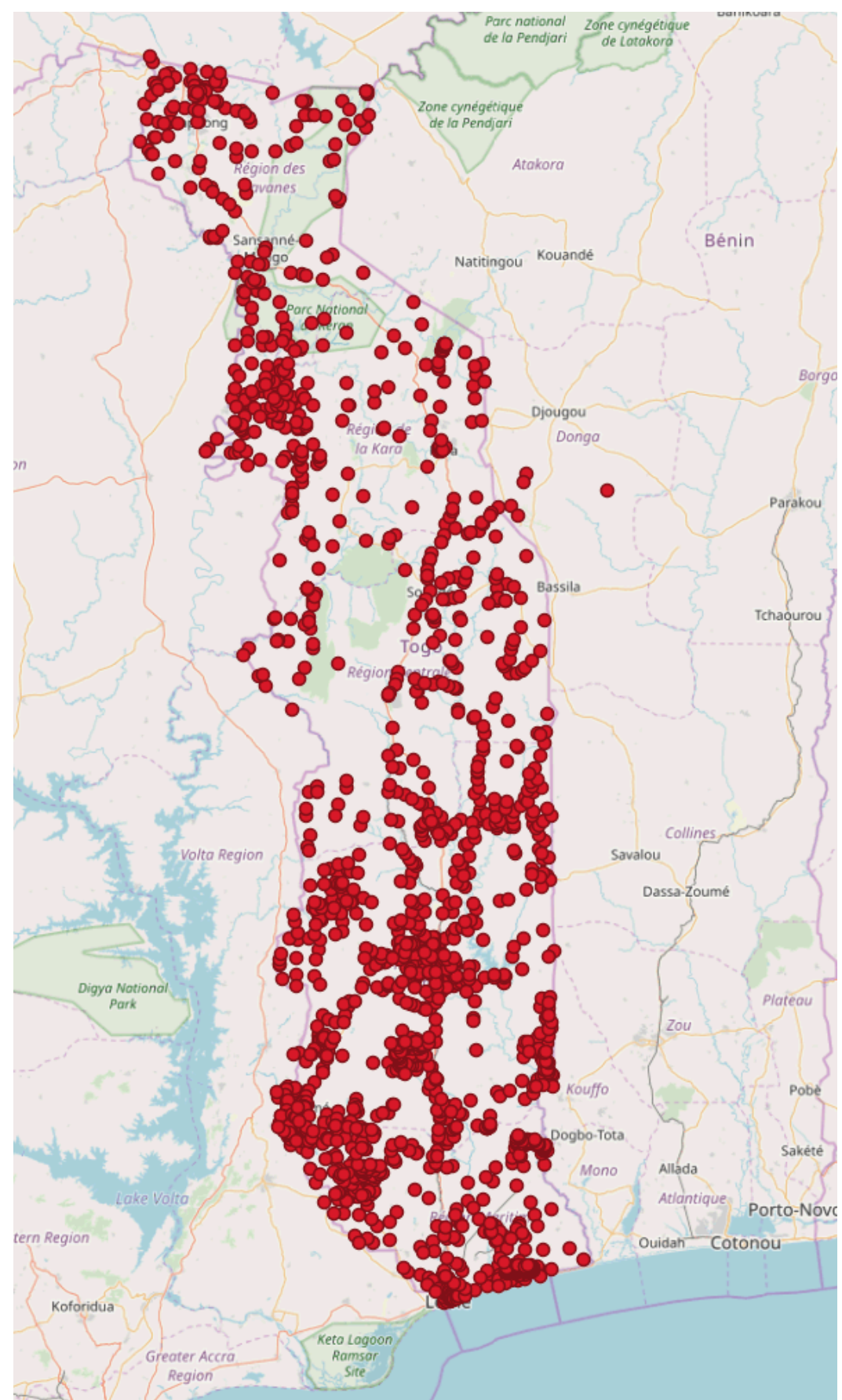

Figure 1. OSM point features (red) showing "places" or human population centers in the OSM Togo data. Some features are located outside of Togo's borders requiring initial data inspection and/or preprocessing to correct these types of errors.

OSM also provides continually updated transportation networks as polyline features. The "roads" spatial layer includes road category information and is critical for route network analysis and supply chain logistics modelling (Figure 2). This data, in conjunction with population centers and biomass supply nodes, can also be used to simulate preprocessing and conversion locations to determine optimal biomass facility locations. 
INL Technical Assistance Program (530117C27)

INL/EXT-18-51742: Water Hyacinth Report

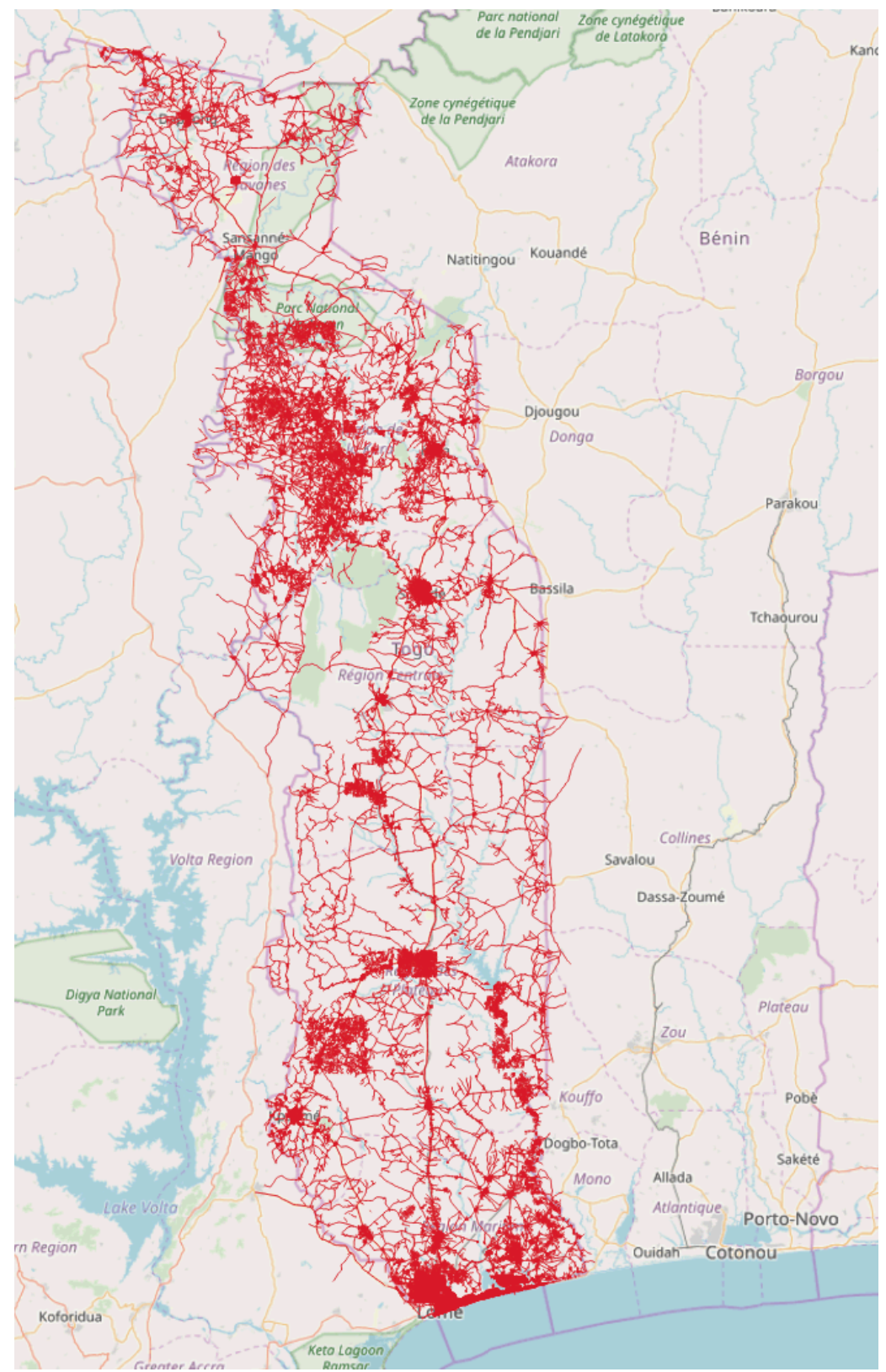

Figure 2. OSM line features (red) showing transportation road networks for Togo.

OSM "water" data delineates bodies of water as polygon features. Categories include reservoirs, large rivers, wetlands, and other types of water bodies. The "waterways" features depict streams, rivers, canals, and other water ways as polyline features. Figure 3 shows the region surrounding Shiroro Lake in Togo including waterways derived from OSM data. 


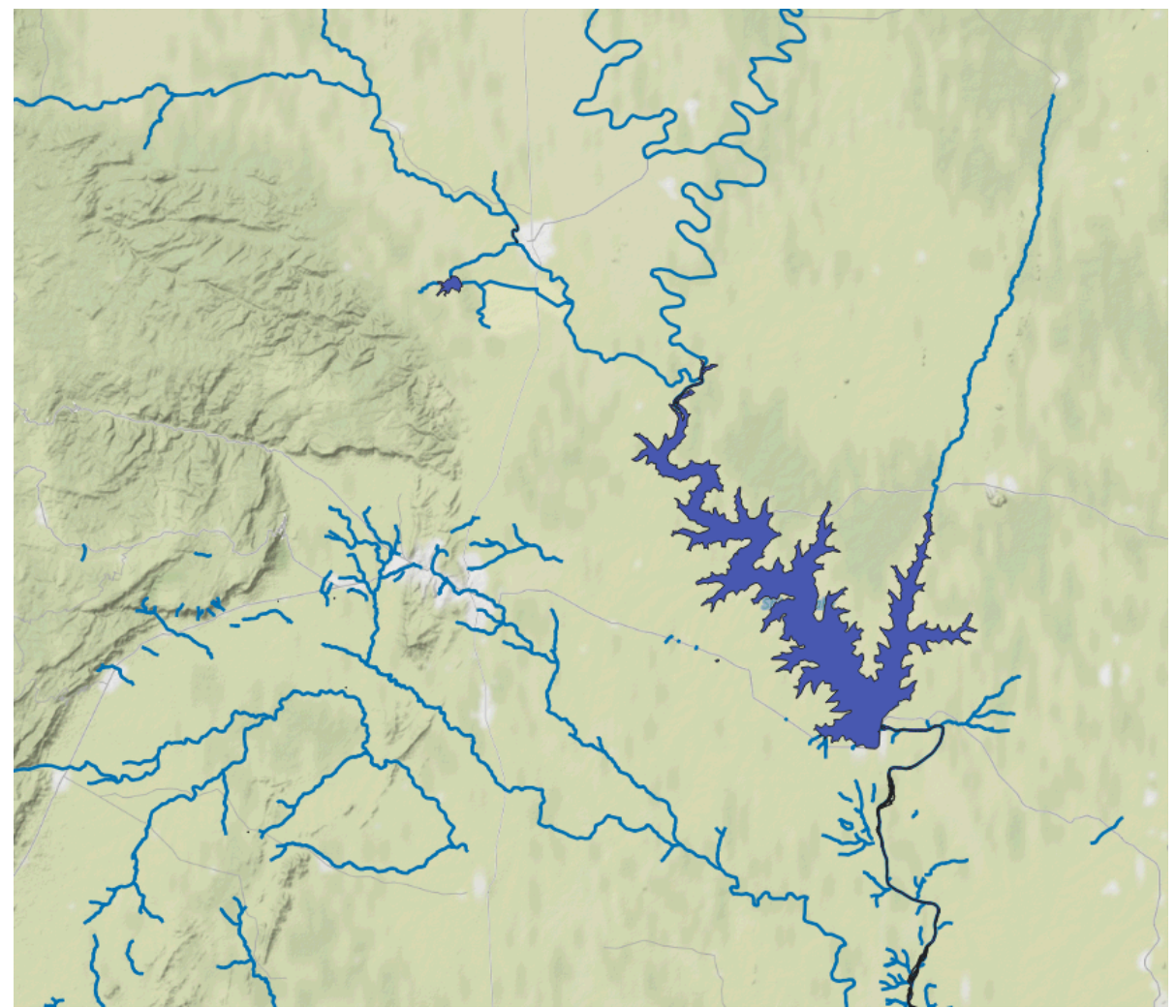

Figure 3. Waterbodies and waterways delineated by blue polygons and lines surrounding the Lake Shiroro region of Togo.

OSM "places", "roads", "waterways", and "water" are comprehensive datasets available for the entire African continent. Although OSM data includes additional features such as places of worship, natural features, and points of interest, it is believed "places", "roads", "waterways", and "water" are most useful to support the development of a water hyacinth biomass feedstock logistics model. Potential harvest and collection sites, transportation networks, and population centers are all key components to model supply chain logistics be it a centralized biorefinery or a disparate energy consumption system akin to individual families utilizing water hyacinth based briquettes for home heating and cooking.

\section{Digital Elevation Models}

Digital Elevation Models (DEMs) are raster datasets denoting elevation values at specific resolutions. DEM data have many uses including topographical and hydrological analysis and modelling plant growth parameters based on micro-climate effects and sunlight interception. DEM data could be useful in developing growth models for water hyacinth as well as the type of terrain surrounding harvest and collection sites. The ASTER Global Digital Elevation Model (ASTER GDEM) is a raster digital elevation set with a spatial resolution of approximately 30 meters (1 arc-second) (NASA/METI/AIST/Japan Spacesystems, 2009). ASTER GDEM was developed jointly by the U.S. National Aeronautics and Space Administration (NASA) and Japan's Ministry of Economy, Trade, and Industry (METI) and is available for land surfaces between 83 degrees $\mathrm{N}$ and 83 degrees $\mathrm{S}$ broken into 22,702 tiles. Figure 4 shows a ASTER GDEM tile for a section of Togo surrounding Shiroro Lake. 


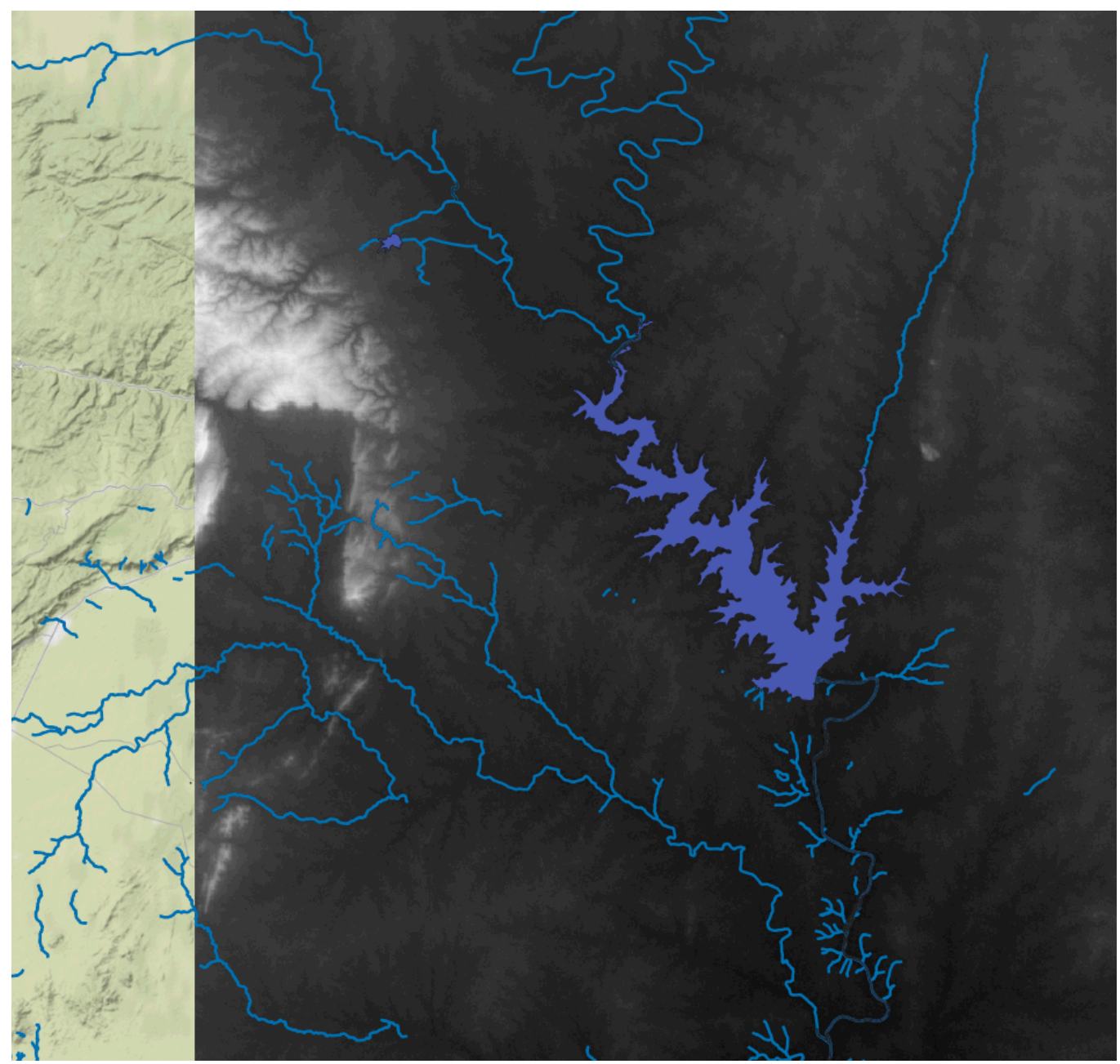

Figure 4. ASTER GDEM data for the Lake Shiroro region of Togo with overlaying water features from Figure 3. Brighter areas indicate higher elevation values.

\section{Remote Sensing Data}

Extensive remote sensing data focused on Earth observation is being collected at everincreasing spectral, spatial, and temporal resolutions via public and private organizations. For the purposes of this report, two relevant publically available resources, the Landsat 8 and Sentinel 2 missions, will be reviewed as they are available at no cost and can be processed in many GIS software packages and show much potential in mapping water hyacinth (Thamaga and Dube, 2018a). These platforms collect high spatial, spectral, and temporal resolution data, appear frequently in peer-reviewed literature, and are commonly used by academic and other research institutions to model plant growth and support land use characterization including water hyacinth.

One of the most well-known Earth observation missions is the Landsat project managed jointly by NASA and the United States Geological Survey. Landsat makes up one of the longest running Earth observation projects having collected remote sensing data on a global scale for over 4 decades. This publically-available data is ideal to map vegetation and assess changes occurring during growing seasons and over periods spanning years. Multiple online portals support searching and download of Landsat products including the latest platform, the Landsat 8 Operation Land Imager (OLI)/Thermal Infrared Sensor (TIRS). Landsat 8 captures nine spectral bands (visible, near infrared, shortwave infrared, and cirrus) at a spatial resolution of 30 meters, 
two thermal infrared bands at a 100-meter spatial resolution, and an additional panchromatic band collected at a 15-meter resolution to produce pan-sharpened data sets for visible and near infrared (NIR) bands (Barsi et al., 2014). Landsat 8 has a 16-day revisit interval and typically provides multiple images in a given growing season depending upon cloud cover.

Dube et al., found that by applying machine learning classification algorithms, Discriminant Analysis (DA) and Partial Least Squares Discriminant Analysis (PLS-DA), water hyacinth could be detected and mapped in freshwater ecosystems with an overall classification accuracy of 95\% (Dube et al., 2017b). Their research shows Landsat 8 bands capturing NIR and shortwave infrared (SWIR) wavelengths including bands 5, 6, 7, 8, 10, and 11 are most influential in detecting and mapping water hyacinth and that DA outperforms PLS-DA. Researchers developed spectral curves for old, intermediate, and young water hyacinth in inland lakes in Zimbabwe from Landsat 8 data finding that portions of visible (band 3), NIR (band 4) and SWIR (band 8, 9, and 10) wavelengths exhibited windows of separability relative to water hyacinth achieving classification accuracies of $72 \%$ (Dube et al., 2017a).

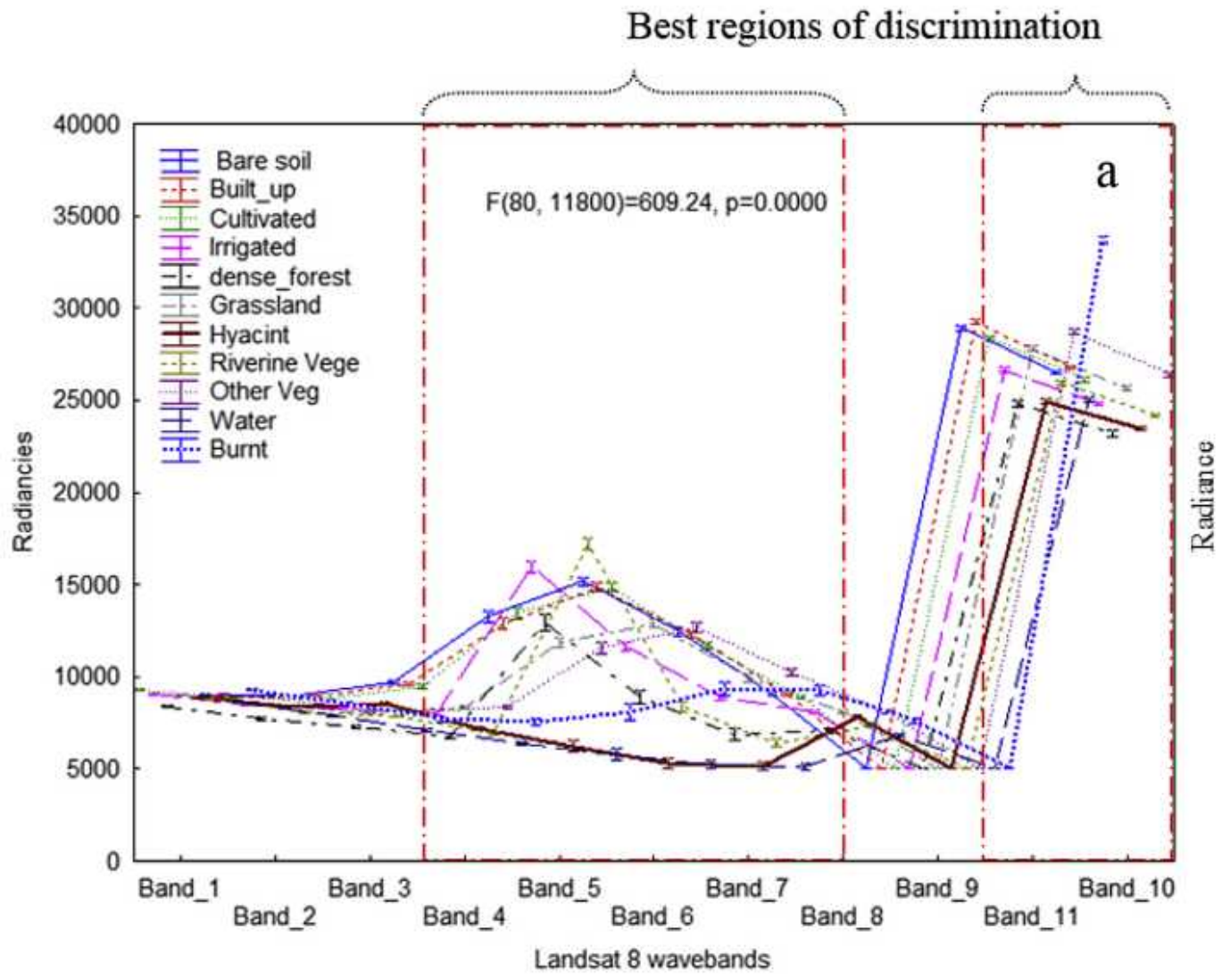

Figure 5. Spectral curves derived from Landsat 8 data showing optimal band regions for water hyacinth discrimination. Source: Dube et al., 2017a.

The European Space Agency's (ESA) Sentinel missions comprise the next level of Earth observation satellites under the Copernicus program, the new name for the Global Monitoring for Environment and Security program. Managed by the European Commission, the data are available freely and openly on a global scale collected by dedicated satellites denoted as "Sentinels"(Berger et al., 2012, ESA). The Sentinel 2 mission is designed for land monitoring at high spatial, spectral, and temporal resolutions and represents an ideal tool to incorporate into a 
model requiring water hyacinth resource assessment. Comprised of Sentinel 2A and Sentinel $2 \mathrm{~B}$, the twin polar-orbiting satellites provide 10 meter spatial resolution data in visible, red edge, NIR, and SWIR bands with a five-day revisit schedule. Depending upon cloud conditions, this platform potentially provides weekly coverage to monitor plant growth and land use characteristics. However, given that the first Sentinel 2 satellite was launched in 2015, the Sentinel mission currently lacks the historical data needed to assess long-term patterns beyond a few years.

Thamaga and Dube evaluated two methods for mapping water hyacinth in the Greater Letaba river system in South Africa using both Landsat 8 and Sentinel 2 data (Thamaga and Dube, 2018b). They found classification of water hyacinth using Sentinel 2 data achieved $77.56 \%$, a significant improvement over Landsat 8 data which yielded a classification accuracy of $68.44 \%$, likely due to the presence of increased spatial and spectral resolutions.

Extensive additional research utilizing hyperspectral sensors and additional platforms exists that were successfully utilized to detect and map water hyacinth using remote sensing and advanced image classifiers. Using these types of technologies have significant advantages over traditional "on-the-ground" field surveys and other methodologies in that cost can be minimized while large areas can be accurately surveyed yield results likely out performing traditional scouting methods.

\section{Geographic Information Systems (GIS) Software}

One of the more common GIS software solutions currently available is QGIS, a user-friendly open source GIS software package licensed under the GNU General Public License (QGIS Development Team, 2018). QGIS is an official project of the Open Source Geospatial Foundation (OSGeo) and is capable of running on most computer operating systems including Microsoft Windows, Mac OSX, and Linux. The software contains a fully functional graphical user interface (GUI) and supports multiple vector and raster data formats including those listed in previous sections. It also integrates other open-source GIS software packages (GDAL, GRASS, SAGA, etc.) as tools supporting hydrological, terrain, remote sensing, and other spatial analysis.

QGIS and other open-source software packages are supported by a community of users contributing code and/or financial resources to continue software development. The software includes standard tools to work with vector and raster data as well as incorporate a variety of basemaps available via streaming services. QGIS supports an ever-expanding library of "plugins", spatial data processing libraries that are designed and compiled to execute specific geoprocessing procedures or algorithms. One such QGIS plugin that would likely be very useful in supporting remote sensing analysis of water hyacinth is the Semi-Automatic Classification Plugin developed by Luca Congedo (Congedo, 2016). This tool allows users to review and download Landsat, Sentinel, and other remote sensing data. It supports data preprocessing including top-of-atmosphere and Dark Object Subtraction (DOS) corrections and supervised classification algorithms. It is an ideal tool to develop and test remote sensing methodologies all within a single software package.

Commercially developed GIS software is also available and would be very suitable to support spatial and remote sensing analysis of water hyacinth distribution mapping. Arguably the most well-known software package was developed by Environmental Systems Research Institute (ESRI) under the ArcGIS portfolio. ArGIS software is limited to the Microsoft Windows operating system and is not available as an open-source product. However, Esri does support various academic institutions with student licenses at reduced cost and also has varying licensing tiers to better fit fees to organizations. ArcGIS also contains an extensive catalogue of spatial analysis tools capable of supporting water hyacinth analysis. Although ArcGIS is not an open-source GIS software package, its extensive use, support, and licensing flexibility make it work including in this section as a viable GIS software option depending upon budget flexibility and user preferences. 
INL/EXT-18-51742: Water Hyacinth Report

\section{Conclusion}

Table 2 shows website addresses for the datasets and software packages discussed in previous sections.

Table 2. Website references and descriptions

\begin{tabular}{|l|l|}
\hline Websites & Description \\
\hline https://www.openstreetmap.org & OpenStreetMap main interface \\
\hline https://download.geofabrik.de/africa.html & $\begin{array}{l}\text { OpenStreetMap data for Africa; } \\
\text { available at continental, regional, and } \\
\text { country levels }\end{array}$ \\
\hline https://lpdaac.usgs.gov & $\begin{array}{l}\text { ASTER Global Digital Elevation } \\
\text { Model (ASTER GDEM) }\end{array}$ \\
\hline https://landsat.usgs.gov/ & Landsat program \\
\hline https://landsat.usgs.gov/landsat-data-access & Landsat data download portals \\
\hline $\begin{array}{l}\text { https://sentinel.esa.int/web/sentinel/sentinel-data- } \\
\text { access }\end{array}$ & ESA Sentinel data access \\
\hline $\begin{array}{l}\text { https://sentinel.esa.int/web/sentinel/missions/sentinel- } \\
2\end{array}$ & Sentinel 2 overview \\
\hline https://www.qgis.org/en/site/about/index.html & QGIS overview \\
\hline $\begin{array}{l}\text { https://www.esri.com/en-us/arcgis/about- } \\
\text { arcgis/overview }\end{array}$ & ArcGIS overview \\
\hline
\end{tabular}

This report outlines spatial data, literature, and software resources with which to develop a robust and scalable water hyacinth resource assessment model. This, in turn, could be used to support a water hyacinth biomass feedstock logistics model to estimate feedstock costs from harvest and collection to conversion. Upon completing this review, the authors believe enough publically available resources exist to develop an initial resource assessment model. At that point, data gaps and resource needs could be assessed to further refine water hyacinth resource assessment.

A path forward to develop a robust water hyacinth biomass feedstock logistics model could be developed as follows:

1. Establish an area of interest representing a likely fuelshed including potential biorefinery sites.

2. Using spatial data and analysis methodologies outlined in this report, develop integrated capabilities to assess location and amounts of water hyacinth in area of interest.

3. Collect detailed information of all equipment that would be used for harvest and collection, transportation, handling, storage, and preprocessing. This includes but is not limited to costs, maintenance requirements, useful life, energy requirements, fuel costs, efficiency metrics, etc.

4. Compile detailed information of necessary human resources including all applicable costs.

5. Integrate everything compiled thus far into a water hyacinth logistics model to simulate harvest and collection, transportation, handling, storage, and preprocessing steps resulting in detailed cost estimates.

6. Using the framework, introduce modelled improvements (equipment, biorefinery location, methodologies, etc.) to reveal potential cost reductions.

\section{References}


BARSI, J. A., LEE, K., KVARAN, G., MARKHAM, B. L. \& PEDELTY, J. A. 2014. The spectral response of the Landsat-8 operational land imager. Remote Sensing, 6, 10232-10251.

BERGER, M., MORENO, J., JOHANNESSEN, J. A., LEVELT, P. F. \& HANSSEN, R. F. 2012. ESA's sentinel missions in support of Earth system science. Remote Sensing of Environment, 120, 84-90.

CONGEDO, L. 2016. Semi-Automatic Classification Plugin Documentation.

CONTRIBUTORS, O. 2012. OpenStreetMap. URL www. openstreetmap. org.

DEMIRBAS, A. H. \& DEMIRBAS, I. 2007. Importance of rural bioenergy for developing countries. Energy Conversion and Management, 48, 2386-2398.

DUBE, T., MUTANGA, O., SIBANDA, M., BANGAMWABO, V. \& SHOKO, C. 2017a. Evaluating the performance of the newly-launched Landsat 8 sensor in detecting and mapping the spatial configuration of water hyacinth (Eichhornia crassipes) in inland lakes, Zimbabwe. Physics and Chemistry of the Earth, Parts A/B/C, 100, 101-111.

DUBE, T., MUTANGA, O., SIBANDA, M., BANGAMWABO, V. \& SHOKO, C. 2017b. Testing the detection and discrimination potential of the new Landsat 8 satellite data on the challenging water hyacinth (Eichhornia crassipes) in freshwater ecosystems. Applied geography, 84, 11-22.

ESA, C. Open Access Hub.

HESS, J. R., WRIGHT, C. T. \& KENNEY, K. L. 2007. Cellulosic biomass feedstocks and logistics for ethanol production. Biofuels, Bioproducts and Biorefining: Innovation for a sustainable economy, 1, 181-190.

KUNATSA, T., MADIYE, L., CHIKUKU, T., SHONHIWA, C. \& MUSADEMBA, D. 2013. Feasibility Study of Biogas Production from Water Hyacinth. International Journal of Engineering and Technology, 3.

LU, J., ZHU, L., HU, G. \& WU, J. 2010. Integrating animal manure-based bioenergy production with invasive species control: A case study at Tongren Pig Farm in China. Biomass and Bioenergy, 34, 821-827.

LYND, L. R., SOW, M., CHIMPHANGO, A. F., CORTEZ, L. A., CRUZ, C. H. B., ELMISSIRY, M., LASER, M., MAYAKI, I. A., MORAES, M. A. \& NOGUEIRA, L. A. 2015. Bioenergy and African transformation. Biotechnology for biofuels, 8, 18.

NASA/METI/AIST/JAPAN SPACESYSTEMS, A. U. S. J. A. S. T. 2009. ASTER Global Digital Elevation Model.

NIGAM, J. 2002. Bioconversion of water-hyacinth (Eichhornia crassipes) hemicellulose acid hydrolysate to motor fuel ethanol by xylose-fermenting yeast. Journal of Biotechnology, 97, 107-116.

QGIS DEVELOPMENT TEAM 2018. QGIS geographic information system. Open Source Geospatial Foundation Project. Disponível em: < http://www. qgis. org/>. Acesso em.

REZANIA, S., DIN, M. F. M., KAMARUDDIN, S. F., TAIB, S. M., SINGH, L., YONG, E. L. \& DAHALAN, F. A. 2016. Evaluation of water hyacinth (Eichhornia crassipes) as a potential raw material source for briquette production. Energy, 111, 768-773.

REZANIA, S., PONRAJ, M., DIN, M. F. M., SONGIP, A. R., SAIRAN, F. M. \& CHELLIAPAN, S. 2015. The diverse applications of water hyacinth with main focus on sustainable energy and production for new era: an overview. Renewable and Sustainable Energy Reviews, 41, 943-954.

THAMAGA, K. H. \& DUBE, T. 2018a. Remote sensing of invasive water hyacinth (Eichhornia crassipes): A review on applications and challenges. Remote Sensing Applications: Society and Environment.

THAMAGA, K. H. \& DUBE, T. 2018b. Testing two methods for mapping water hyacinth (Eichhornia crassipes) in the Greater Letaba river system, South Africa: discrimination 
INL Technical Assistance Program (530117C27)

INL/EXT-18-51742: Water Hyacinth Report

and mapping potential of the polar-orbiting Sentinel-2 MSI and Landsat 8 OLI sensors. International Journal of Remote Sensing, 1-19. 